\title{
FDG and FMISO PET-guided dose escalation with intensity-modulated radiotherapy in lung cancer
}

Sébastien Thureau ${ }^{1,2^{*}}$, Bernard Dubray ${ }^{1}$, Romain Modzelewski ${ }^{2}$, Pierre Bohn², Sébastien Hapdey ${ }^{2}$, Sabine Vincent ${ }^{1}$, Elodie Anger ${ }^{1}$, David Gensanne ${ }^{1}$, Nicolas Pirault ${ }^{1}$, Gouel Pierrick ${ }^{2}$ and Pierre Vera ${ }^{2}$

\begin{abstract}
Background: Concomitant chemo-radiotherapy is the reference treatment for non-resectable locally-advanced NonSmall Cell Lung Cancer (NSCLC). Increasing radiotherapy total dose in the whole tumour volume has been shown to be deleterious. Functional imaging with positron emission tomography (PET/CT) offers the potential to identify smaller and biologically meaningful target volumes that could be irradiated with larger doses without compromising Organs At Risk (OAR) tolerance. This study investigated four scenarios, based on ${ }^{18} \mathrm{FDG}$ and ${ }^{18} \mathrm{~F}$-miso PET/CT, to delineate the target volumes and derive radiotherapy plans delivering up to 74Gy.
\end{abstract}

Method: Twenty-one NSCLC patients, selected from a prospective phase II trial, had ${ }^{18} \mathrm{FDG}$ - and ${ }^{18} \mathrm{~F}$-miso PET/CT before the start of radiotherapy and ${ }^{18} \mathrm{FDG}$ PET/CT during the radiotherapy (42Gy). The plans were based planned on a standard plan delivering 66 Gy (plan 1) and on three different boost strategies to deliver 74Gy total dose in pre-treatment ${ }^{18} \mathrm{FDG}$ hotspot (70\% of SUV max $_{\text {) }}$ (plan 2), pre-treatment ${ }^{18} \mathrm{~F}$-miso target (SUV $\max >1.4$ ) (plan 3) and per-treatment ${ }^{18} \mathrm{FDG}$ residual (40\% of SUV $\left.V_{\max }\right)$. (plan 4).

Results: The mean target volumes were $4.8 \mathrm{cc}( \pm 1.1)$ for ${ }^{18} \mathrm{FDG}$ hotspot, $38.9 \mathrm{cc}( \pm 14.5)$ for ${ }^{18} \mathrm{~F}$-miso and $36.0 \mathrm{cc}( \pm 10.1)$ for per-treatment ${ }^{18} \mathrm{FDG}$. In standard plan (66 Gy), the mean dose covering 95\% of the PTV (D95\%) were $66.5( \pm 0.33), 66.1$ $( \pm 0.32)$ and $66.1( \pm 0.32)$ Gy for ${ }^{18} \mathrm{FDG}$ hotspot, ${ }^{18} \mathrm{~F}$-miso and per-treatment ${ }^{18} \mathrm{FDG}$. In scenario 2, the mean D95\% was 72. $5( \pm 0.25)$ Gy in ${ }^{18} \mathrm{FDG}$ hotspot versus $67.9( \pm 0.49)$ and $67.9 \mathrm{~Gy}( \pm 0.52)$ in ${ }^{18} \mathrm{~F}$-miso and per-treatment ${ }^{18} \mathrm{FDG}$, respectively. In scenario 3, the mean D95\% was $72.2( \pm 0.27)$ Gy to ${ }^{18}$ F-miso versus $70.4( \pm 0.74)$ and $69.5 \mathrm{~Gy}( \pm 0.74)$ for ${ }^{18} \mathrm{FDG}$ hotspot and per-treatment ${ }^{18} \mathrm{FDG}$, respectively. In scenario 4, the mean D95\% was 73.1 ( \pm 0.3 ) Gy to ${ }^{18} \mathrm{FDG}$ per-treatment versus $71.9( \pm 0.61)$ and $69.8( \pm 0.61)$ Gy for ${ }^{18}$ FDG hotspot and ${ }^{18} \mathrm{~F}-\mathrm{miso}$, respectively. The dose/volume constraints to OARs were matched in all scenarios.

Conclusion: Escalated doses can be selectively planned in NSCLC target volumes delineated on ${ }^{18} \mathrm{FDG}$ and ${ }^{18} \mathrm{~F}$-miso PET/CT functional images. The most relevant strategy should be investigated in clinical trials.

Trial registration: (RTEP5, NCT01576796, registered 15 june 2012)

Keywords: Positron emission tomography, ${ }^{18}$ fluoro-deoxy-D-glucose, ${ }^{18}$ fluoro-misonidasole, Lung cancer, Hypoxia, Radiotherapy

\footnotetext{
* Correspondence: sebastien.thureau@chb.unicancer.fr

'Department of Radiation Oncology and Medical Physics, Centre Henri

Becquerel, QuantIF - LITIS [EA 4108], Université de Normandie, CS 11516, rue d'Amiens, 76038 Rouen Cedex 1, France

${ }^{2}$ Department of Nuclear Medicine, Henri Becquerel Cancer Center and Rouen University Hospital, \& QuantIF - LITIS [EA (Equipe d'Accueil) 4108 - FR CNRS 3638], Faculty of Medicine, University of Rouen, Rouen, France
}

(c) The Author(s). 2018 Open Access This article is distributed under the terms of the Creative Commons Attribution 4.0 International License (http://creativecommons.org/licenses/by/4.0/), which permits unrestricted use, distribution, and reproduction in any medium, provided you give appropriate credit to the original author(s) and the source, provide a link to the Creative Commons license, and indicate if changes were made. The Creative Commons Public Domain Dedication waiver (http://creativecommons.org/publicdomain/zero/1.0/) applies to the data made available in this article, unless otherwise stated. 


\section{Background}

Non-small cell lung cancer (NSCLC) is a deadly disease. The majority of non-metastatic NSCLC cannot undergo surgical resection with curative-intent, either due to the patient's medical condition or to cancer local extension. Concomitant Radiotherapy - Chemotherapy (RTCT) is the standard curative-intent treatment for non-operable patients/non resectable cancers [1]. Large efforts in radiotherapy techniques are made to improve tumour control and survival $[1,2]$. A total dose $>60$ Gy to the entire tumour volume defined on CT or PET was deleterious in the RTOG 0617 randomized trial [3]. Many relapses occur within the radiotherapy target volume, suggesting insufficient total dose $[4,5]$. Reducing the target volume to high recurrence risk areas is assumed to allow isotoxic dose escalation. Experimental and clinical data have shown that tumour subvolumes defined by high ${ }^{18}$ F-FDG (metabolic hotspot) or ${ }^{18} \mathrm{~F}$-misonidazole $\left({ }^{18} \mathrm{~F}\right.$-miso) uptake are associated to recurrence and cancer death [6].

In a phase II study (NCT01576796, RTEP5 study), we used ${ }^{18} \mathrm{~F}$-miso to identify and delineate hypoxic areas within the ${ }^{18}$ FDG-defined Gross Target Volume (GTV) [7]. The total radiotherapy dose was safely increased in 24 out of 34 patients with ${ }^{18} \mathrm{~F}$-miso uptake. Doses up to 86 Gy could not reverse the poor prognosis features of ${ }^{18} \mathrm{~F}$-miso positive tumours. In this study, hypoxic tumours with boost had the same local control despite twice as large volumes. The patients' data were used to test in silico three strategies for selective increase in total dose, based on functional imaging. For the strategies with boost, we tested at a dose of 74 Gy to be comparable to the study of Bradley et al. [3] and our current phase II/III (RTEP7; NCT02473133). In 21 patients, a standard plan (66 Gy to whole Planning Target Volume PTV plan 1) to 74 Gy was compared to the pre-RT ${ }^{18}$ FDG metabolic hotspot (70\% of SUVmax) (plan 2), 2/ the pre-RT ${ }^{18} \mathrm{~F}$-MISO-affine (SUV > 1.4) volume (plan 3 ) or the per-treatment ${ }^{18} \mathrm{FDG}$ uptake (40\% of SUVmax) (plan 4).

\section{Methods}

\section{Study design and patients}

The details of the study can be found elsewhere [7]. Fifty-four patients with NSCLC, eligible for curative-intent RTCT, and with significant FDG uptake on pre-RT PET/ CT were prospectively selected. The 21 patients with significant per-RT F-miso uptake and meeting the dose/ volume constraints for the organs at risk (OAR) form the basis of the present study (Fig. 1). All the patients had signed a written consent to participate to RTEP5.

\section{$\mathrm{PET} / \mathrm{CT}$ imaging}

Two ${ }^{18} \mathrm{FDG}$ PET/CT $\left(\mathrm{FDG}_{1}\right.$ and $\mathrm{FDG}_{2}$ ) and two ${ }^{18} \mathrm{~F}$-miso $\mathrm{PET} / \mathrm{CT}$ (F-miso ${ }_{1}$ and F-miso ${ }_{1}$ ) acquisitions were performed before and during RT using the same machine and under the identical operational conditions, a centrally supervised quality control securing homogeneity in the image quality in all centres [7]. $\mathrm{FDG}_{1}$ was acquired in treatment position (arms over the head, free breathing), at least 15 days after the last administration of chemotherapy. F-miso ${ }_{1}$ was scheduled $48 \mathrm{~h}$ after the FDG1. The F-miso PET/CT acquisitions were reviewed by 3 independent experts (out of the 9 experts) who decided upon the presence or absence of uptake [8]. The CT scan images were used to register all PET/CT acquisitions, delineate target volumes and plan radiotherapy. Respiratory-gated 4D acquisitions were not performed. No further chemotherapy was allowed between $\mathrm{FDG}_{1} /$ F-miso ${ }_{1}$ and the start of radiotherapy. The F-miso ${ }_{2}$ was not associated with a planification due to the very low contrast in per-treatment [7].

\section{Target volume definition}

For each patient, the CTs of $\mathrm{FDG}_{1}, \mathrm{FDG}_{2}$ and F-miso ${ }_{1}$ were co-registered to the planning CT scanner (Oncoplanet, DosiSoft, France, v 1.4), focusing on the tumour. The GTV for $\mathrm{FDG}_{1}$ was defined as the sum of the voxels with uptake $>40 \%$ of the SUVmax inside primary tumour or nodes and corrected from CT data. The ${ }^{18}$ FDG hotspot was defined as all voxels with uptake $>70 \%$ of the SUVmax inside the primary tumour or nodes (BTVm1). The hypoxic volume (BTVh) was defined as the sum of voxels with SUV $\geq 1.4$ on F-miso ${ }_{1}[7,8]$. The residual volume on FDG PET/ CT2 (BTVm2) was defined as the sum of the voxels with uptake $>40 \%$ of the SUVmax inside the primary tumour or nodes. The co-registered volumes were then transferred to an Eclipse planning platform (V13.6, Varian Inc.). The CTV66 were obtained either by isotropic expansion around the primary tumour $(6 \mathrm{~mm}$ for squamous cell carcinoma, $8 \mathrm{~mm}$ for adenocarcinoma), then manually edited to exclude the bones, the large vessels and heart, the muscle and the trachea, or by anatomical delineation of the involved nodal stations $[9,10]$. The margins around the BTVs or CTVs to delineate the Planning Target Volume (PTV) were 10 to $15 \mathrm{~mm}$. All delineation were performed by an experienced radiation oncologist (ST).

\section{Planning scenarios}

Four IMRT by step and shoot scenarios were applied in each patient. All the dose calculations were corrected for heterogeneity (V13.6, AAA v10.0.28 Varian Inc.) and for the optimization (DVO v10.0.28, Varian Inc). The total dose was prescribed at ICRU point, the dose delivered in the PTV having to be within $95 \%$ and $107 \%$ of the prescribed dose. Absolute priority constraints were a maximum dose to the spinal cord $<45 \mathrm{~Gy}$ and no more than $30 \%$ of the total lung volume (excluding the PTV) receiving $\geq 20$ Gy (V20Gy). The secondary dose/volume 


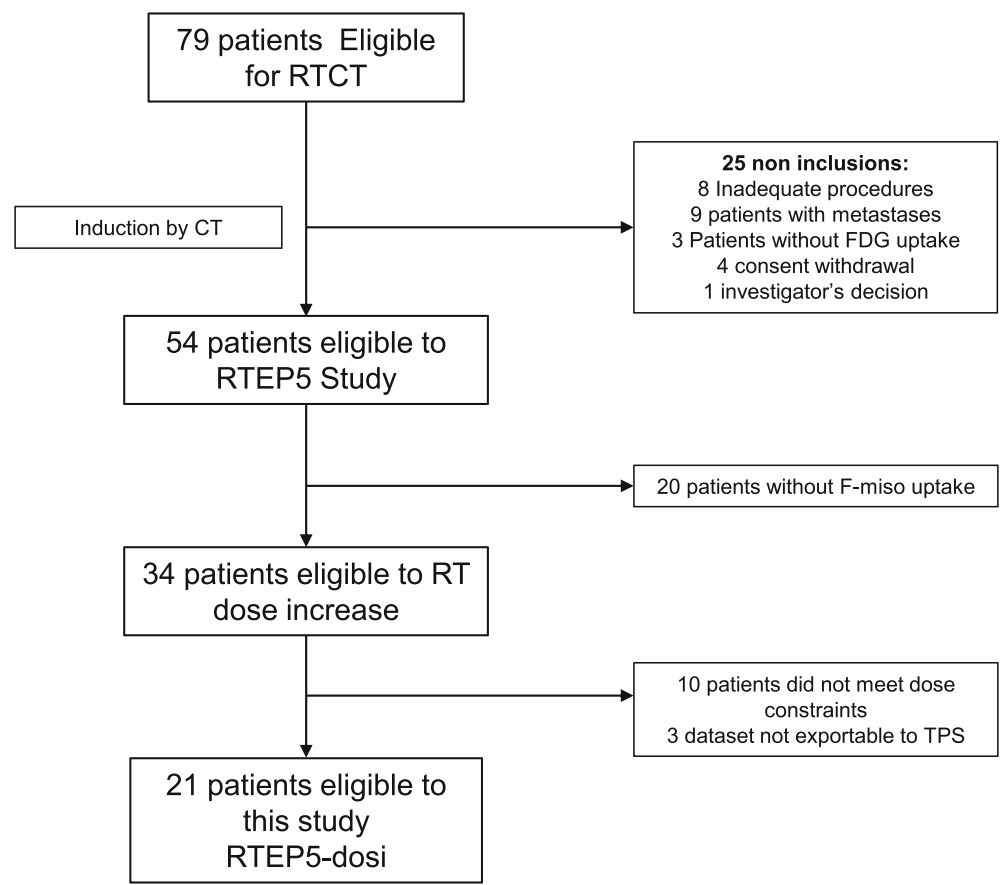

Fig. 1 Study design. RTCT: radio-chemotherapy; TPS: Treatment Planning System

constraints were no more than $30 \%$ of the oesophagus or the heart receiving $\geq 50$ or $\geq 35 \mathrm{~Gy}$, respectively.

The first scenario (standard or reference plan; plan 1) was to deliver 66 Gy in the PTV based on FDG1. The experimental scenarios had to deliver 66 Gy in the FDG1 PTV (PTV66) and an additional dose up to 74 Gy in three different smaller target volumes. The boost target volumes were the metabolic hotspot on pre-treatment FDG PET/ CT (BTVm1, scenario 2), the hypoxic volume on pre-treatment F-miso PET/CT (BTVh, scenario 3), and the residual uptake on the FDG PET/CT at 42 Gy (BTVm2, scenario 4). The treatment was planned with a simultaneous boost from the start of the radiotherapy for plan 2 and 3 and from 50 Gy for the plan 4.

\section{Statistical analyses}

Descriptive statistics ( $\mathrm{n}$, mean, SE minimum and maximum) were calculated for the quantitative variables. Frequency and percentages with 95\% confidence intervals (CI) were computed for the qualitative variables. Levene's test was used to assess variances equality when comparing the quantitative variables means between two or more groups (ANOVA). All statistical calculations were performed with MedCalc Software (version16.2.0, Ostend, Belgium).

\section{Results}

\section{Population}

The present study was based on 21 patients ( 4 women and 20 men, mean age $( \pm S E)=59 \pm 8$ years $)$. There were
7 adenocarcinomas, 12 squamous cell carcinomas and 2 undifferentiated carcinomas. The stages distribution was 1 IIB, 12 IIIA and 8 IIIB (Table 1).

\section{Target volumes and dose distribution}

The mean $\mathrm{CTV}_{66 \mathrm{~Gy}}$ was $244 \pm 50 \mathrm{cc}$, larger than all BTVs. The ${ }^{18}$ FDG hotspot (BTV FDG 70\%) smaller than the BTV FDG per-RT $(4.8 \pm 1.1$ versus $36 \pm 10 \mathrm{cc}, p=0.03)$ and the BTV hypoxic ( $39 \pm 15 \mathrm{cc}, p=0.13)$. Similarly, the mean PTV 66 Gy was $473 \pm 69$ cc versus $35 \pm 5.8 \mathrm{cc}$ for PTV FDG 70\%, $111 \pm 24$ cc for PTV FDG per-RT, and $105 \pm$ 26 cc for PET F-miso (Table 1).

In scenarios 2, 3 and 4, the mean doses to the specific target volume was higher than the doses given to the other biological volumes or PTV 66 Gy. In scenario 2 (boost to ${ }^{18}$ FDG hotspot), the mean dose to $95 \%$ of the PTV (D95\%) was $72.5(( \pm 0.25)$ Gy versus $67.9( \pm 0.49)$ $(p<0.0001)$ in F-miso PTV and 67.9 Gy $( \pm 0.52)(p<$ $0.0001)$ in per-treatment ${ }^{18} \mathrm{FDG}$ PTV. In scenario 3 (boost to ${ }^{18} \mathrm{~F}$-miso), the mean D95\% was $72.2( \pm 0.27)$ Gy versus $70.4( \pm 0.33)(p=0.74)$ in ${ }^{18}$ FDG hotspot and $69.5( \pm 0.74)$ Gy $(p=0.009)$ in per-treatment ${ }^{18} \mathrm{FDG}$ PTV. In scenario 4 (boost to per-treatment ${ }^{18} \mathrm{FDG}$ ), the mean D95\% was $73.1( \pm 0.3)$ Gy versus $71.9( \pm 0.61)(p=0.2)$ in ${ }^{18}$ FDG hotspot and $69.8( \pm 0.61)$ Gy $(p=0.0001)$ to FMISO PTV (Fig. 2). The results are presented for CTV (Table 2), PTV (Table 3) and Organs at Risk (Table 4).

The dose/volume constraints to the organs at risk were matched without significant differences between scenarios except to the heart between the plan to 66 Gy and FDG 
Table 1 Baseline characteristics of 21 included patients

\begin{tabular}{|c|c|c|c|c|c|c|c|c|c|c|}
\hline \multirow[t]{2}{*}{ Patient } & \multirow[t]{2}{*}{ Gender } & \multirow[t]{2}{*}{ Age } & \multirow[t]{2}{*}{ TNM } & \multirow[t]{2}{*}{ Stage } & \multirow[t]{2}{*}{ Pathology } & \multicolumn{5}{|c|}{ Volume (cm3) } \\
\hline & & & & & & CTV 66Gy & BTV FDG $40 \%$ & BTV FDG 70\% & BTV FMISO & BTV FDG perRT \\
\hline 1 & $\mathrm{~F}$ & 51 & T3N3M0 & $\| \mathrm{IIB}$ & Adenocarcinoma & 157.2 & 21.1 & 3.0 & 1.9 & 18.7 \\
\hline 2 & M & 64 & T4NOMO & $\| \mathrm{A}$ & Squamous cell carcinoma & 512.6 & 186.5 & 6.9 & 75.3 & 162.0 \\
\hline 3 & $\mathrm{~F}$ & 59 & T1N2M0 & $\| \mathrm{IIA}$ & Adenocarcinoma & 68.5 & 9.9 & 7.6 & 2.4 & 2.3 \\
\hline 4 & M & 51 & T1N3M0 & $\| \mathrm{II}$ & Adenocarcinoma & 45.8 & 15.1 & 2.4 & 0.1 & 5.1 \\
\hline 5 & M & 59 & T3N3M0 & $\| \mathrm{B}$ & Adenocarcinoma & 273.2 & 87.2 & 6.4 & 8.3 & 78.7 \\
\hline 6 & $\mathrm{~F}$ & 60 & T3N2M0 & $\| \mathrm{A}$ & Adenocarcinoma & 648.7 & 189.5 & 6.1 & 143.1 & 132.1 \\
\hline 7 & M & 76 & T2NOMO & $\| \mathrm{A}$ & Squamous cell carcinoma & 56.8 & 13.8 & 5.0 & 2.3 & 2.8 \\
\hline 8 & $\mathrm{~F}$ & 62 & T2N2M0 & $\| \mathrm{A}$ & Squamous cell carcinoma & 116.3 & 6.3 & 0.2 & 4.4 & 1.1 \\
\hline 9 & M & 63 & T4N1M0 & $\| \mathrm{A}$ & Squamous cell carcinoma & 236.1 & 19.2 & 0.2 & 5.7 & 8.9 \\
\hline 10 & M & 65 & T4N2M0 & $\| \mathrm{B}$ & Squamous cell carcinoma & 157.4 & 14.9 & 0.3 & 26.1 & 9.1 \\
\hline 11 & M & 72 & T3N2M0 & $\| \mathrm{II}$ & Squamous cell carcinoma & 289.4 & 101.1 & 19.1 & 272.5 & 75.8 \\
\hline 12 & M & 59 & T4N3M0 & $\| \mathrm{II}$ & Squamous cell carcinoma & 290 & 37.2 & 7.6 & 36.8 & 15.4 \\
\hline 13 & M & 55 & T4N2M0 & $\| \mathrm{IIB}$ & Squamous cell carcinoma & 970.9 & 353.2 & 6.7 & 100.8 & 87.6 \\
\hline 14 & M & 58 & T4NOMO & $\| \mathrm{IIB}$ & Squamous cell carcinoma & 283.7 & 72.6 & 15.1 & 81.1 & 34.0 \\
\hline 15 & M & 45 & T3N2M0 & $\| \mathrm{II}$ & Squamous cell carcinoma & 80.5 & 30.5 & 0.4 & 16.1 & 9.2 \\
\hline 16 & M & 54 & T2N2MO & $\| I I A$ & Adenocarcinoma & 64.4 & 9.4 & 0.6 & 2.4 & 5.1 \\
\hline 17 & M & 61 & T4N2M0 & $\| \mathrm{IIB}$ & Squamous cell carcinoma & 241.1 & 22.6 & 0.9 & 24.2 & 64.4 \\
\hline 18 & M & 58 & T3NOMO & $\| B$ & Unknow & 90.4 & 8.8 & 2.5 & 7.9 & 9.1 \\
\hline 19 & M & 63 & T2N2M0 & $\| \mathrm{II}$ & Adenocarcinoma & 328.8 & 9.5 & 0.5 & 1.8 & 10.2 \\
\hline 20 & M & 70 & T3N2M0 & $\| \mathrm{II}$ & Squamous cell carcinoma & 135 & 24.3 & 1.6 & 0.2 & 4.8 \\
\hline 21 & M & 42 & TON2MO & IIIA & Unknow & 82.1 & 29.4 & 8.0 & 2.8 & 19.7 \\
\hline mean & & 59 & & & & 244.2 & 60.1 & 4.8 & 38.9 & 36 \\
\hline SE & & 8 & & & & 49.6 & 18.8 & 1.1 & 14.5 & 10.1 \\
\hline
\end{tabular}
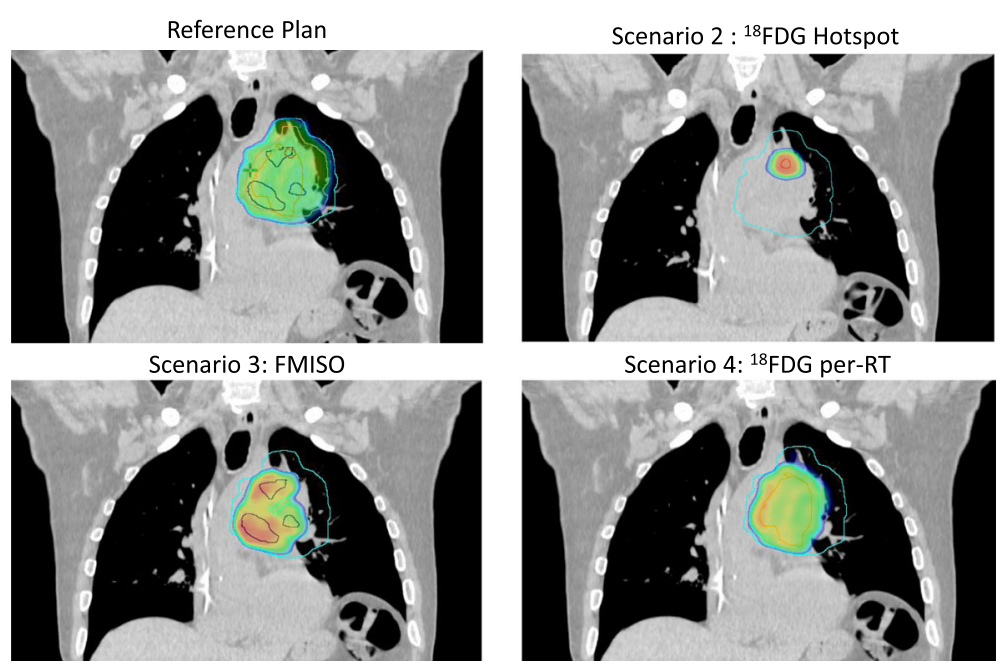

Fig. 2 Example of dosimetry. Representation of dose (95\% to maximum dosi) fr reference plan (66Gy) and three scenario of planification based on PET. PTV are blue, hotspot (BTVm1) is red, FDG pre-RT (BTVm2) is orange and FMISO (BTVh) is dark blue. For each plan the PTV 66 is represented 
Table 2 Comparison of dose to PTV for 4 planning treatment: PTV66, PTV FDG 70\%, PTV F-miso, PTV FDG 42 Gy

\begin{tabular}{lllllll}
\hline Scenario & Boost target volume & \multicolumn{2}{l}{ Mean doses (SE) to target volumes } & & & \\
\cline { 3 - 6 } & & PTV66 & PTV FDG 70\% & PTV FMISO & PTV FDG 42Gy & $p$ value \\
\hline Reference plan (66Gy) & & $\mathbf{6 2 . 3}( \pm 0.38)$ & $66.5( \pm 0.33)$ & $66.1( \pm 0.32)$ & $66.1( \pm 0.32)$ & NA \\
Scenario 2 & FDG Hotspot & $62.7( \pm 0.4)$ & $\mathbf{7 2 . 5}( \pm 0.25)$ & $67.9( \pm 0.49)$ & $67.9( \pm 0.52)$ & 0.001 \\
Scenario 3 & Fmiso & $62.6( \pm 0.42)$ & $70.4^{*}( \pm 0.74)$ & $\mathbf{7 2 . 2 *}( \pm 0.27)$ & $69.5( \pm 0.74)$ & 0.001 \\
Scenario 4 & FDG per treatment & $63.7( \pm 0.36)$ & $71.9^{*}( \pm 0.61)$ & $69.8( \pm 0.61)$ & $\mathbf{7 3 . 1}^{*}( \pm 0.3)$ & 0.001 \\
\hline
\end{tabular}

Data in boldface is the reference dose by plan

*no significant difference

per-treatment plan with $\mathrm{V} 35$ at respectively $5 \%( \pm 1.7)$ and $5.4 \%( \pm 1.8)(p=0.05)$ (Table 4$)$.

\section{Discussion}

The present planning study confirms that selecting various sub-volumes to increase radiotherapy total dose results in different dose distributions. The data of 21 patients were retrieved from a prospective phase II study investigating the clinical feasibility of boosting the radiotherapy dose in tumour hypoxic areas delineated on ${ }^{18} \mathrm{~F}$-miso PET/CT. Pre- and per-radiotherapy ${ }^{18}$ FDG allowed us to compare three different biologically-oriented strategies.

RTCT is the reference treatment for locally advanced non operable NSCLC. The high incidence of relapse within the target volume suggest insufficient total doses of radiotherapy to achieve local control. The RTOG 0617 randomized trial [3] demonstrated that an indiscriminate dose increase in all patients and to the entire ${ }^{18} \mathrm{FDG}$ PET/CT volume was deleterious. The combination of functional information (metabolism or hypoxia) and improved radiotherapy delivery (IMRT) opens the way to selectively increase total dose in biologically-relevant parts of the tumour. In a previous study, we showed that areas of high ${ }^{18}$ FDG uptake (SUV > 70\% SUVmax) on pre-treatment PET/CT scans were associated to tumour areas at greater risk of relapse [11]. Similar results have been reported in NSCLC [12] and in oesophageal cancer patients [13]. A European randomized phase II is currently investigating an integrated boost up to $72 \mathrm{~Gy}$ in the $>50 \%$ SUV$\max$ volume delineated on pre-treatment ${ }^{18} \mathrm{FDG}$ PET/CT (PET Boost; NCT01024829). We are presently conducting a phase II study (RTEP7; NCT02473133) where the radiotherapy dose is escalated up to 74 Gy in the metabolic residual as assessed on FDG-PET/CT performed at $42 \mathrm{~Gy}$. Targeting the hypoxic volume as identified by ${ }^{18} \mathrm{~F}$-miso PET/CT before or during radiotherapy was investigated in RTEP5 [7] and RTOG-1106 (NCT01507428) trials, respectively, as well as in head and neck cancer patients $[14,15]$.

The three scenarios investigated here yielded different target volumes for radiotherapy dose escalation. Our data contradict the idea that ${ }^{18}$ FDG uptake is associated to the presence of hypoxia via the upregulation of glucose transporter 1 by hypoxia-inducible factor $1[16,17]$. ${ }^{18} \mathrm{FDG}$ and ${ }^{18} \mathrm{~F}$-miso provide different and possibly complementary information. Given the impact on dose distribution as observed here, the selection of the most relevant strategy will rely on clinical trials. In our RTEP5 phase II [7], the patients with significant 18F-miso uptake had worse disease-free and overall survival probabilities. This observation questions the assumption that hypoxia-related radioresistance could be overcome by moderate additional doses targeted to the hypoxic volume. On the other hand, most of the dose escalation trials (including our RTEP5 phase II) achieved higher doses by adding several 2-Gy fractions to the reference irradiation schedule. The protraction of radiotherapy (up to 7.5 weeks in RTOG 0617) is known to favour tumour cell proliferation and to reduce the probability of tumour control. In our ongoing RTEP7 phase II, the boost is given by fractions of 3 Gy to avoid longer treatment times. In the present scenarios, IMRT allows to delivered simultaneous integrated boost (2 Gy per fraction in PTV66 and 2.24 Gy per fraction in the boost defined on pre-treatment PET/CT. Note that scenario 4 requires a 2-step planning (up to $50 \mathrm{~Gy}$, then up to 74 Gy with 8 fractions of $3 \mathrm{~Gy}$. Other approaches could be proton therapy [18] or stereotaxic radiotherapy [19].

Table 3 Comparison of dose to CTV or BTV for 4 planning treatment: CTV66, BTV FDG 70\%, BTV F-miso, BTV FDG 42 Gy

\begin{tabular}{|c|c|c|c|c|c|c|}
\hline \multirow[t]{2}{*}{ Scenario } & \multirow[t]{2}{*}{ Boost target volume } & \multicolumn{4}{|c|}{ Mean ( \pm SE) doses to target volumes (Gy) } & \multirow[b]{2}{*}{$p$ value } \\
\hline & & CTV66 & BTV FDG 70\% & BTV FMISO & BTV FDG 42Gy & \\
\hline Reference plan (66 Gy) & & $65.1( \pm 0.35)$ & $67.1( \pm 0.32)$ & $66.9( \pm 0.38)$ & $66.8( \pm 0.39)$ & $N A$ \\
\hline Scenario 2 & ${ }^{18}$ FDG Hotspot & $65.9( \pm 0.47)$ & $74.3( \pm 0.32)$ & $70.4( \pm 0.86)$ & $70.4( \pm 0.88)$ & 0.001 \\
\hline Scenario 3 & ${ }^{18} \mathrm{~F}$-miso & $65.9( \pm 0.53)$ & $72.6( \pm 0.86)$ & $74.6( \pm 0.33)$ & $71.7( \pm 0.9)$ & 0.001 \\
\hline Scenario 4 & ${ }^{18} \mathrm{FDG}$ per $\mathrm{RT}$ & $66.8( \pm 0.42)$ & $73.5( \pm 0.68)$ & $72.5( \pm 0.7)$ & $74.6( \pm 0.31)$ & 0.001 \\
\hline
\end{tabular}

Data in boldface is the reference dose by plan 
Table 4 Comparison of dose to organs at risk for 4 planning treatment: PTV66, PTV FDG 70\%, PTV F-miso, PTV FDG 42 Gy

\begin{tabular}{llllll}
\hline \multirow{2}{*}{ Scenario } & Boost target volume & \multicolumn{4}{l}{ Dose-volume constraint to organ at risk } \\
\cline { 3 - 6 } & & Mean lung dose (Gy) & D2\% spinal cord (Gy) & V35 heart (\%) & V50 oesophagus (\%) \\
\hline Reference plan & & $11.5( \pm 0.5)$ & $32.7( \pm 2.1)$ & $5^{* *}( \pm 1.7)$ & $20.5( \pm 2.7)$ \\
Scenario 2 & FDG Hotspot & $11.7( \pm 0.5)$ & $32( \pm 2.1)$ & $5.3( \pm 1.8)$ & $20.4( \pm 2.6)$ \\
Scenario 3 & Fmiso & $11.8( \pm 0.5)$ & $31.6( \pm 2.1)$ & $5.2( \pm 1.9)$ & $21( \pm 2.6)$ \\
Scenario 4 & FDG per treatment & $13.4( \pm 1.5)$ & $32.2( \pm 2.3)$ & $5.4^{* *}( \pm 1.8)$ & $20.8( \pm 2.7)$ \\
$p$ value & & 0.2 & 0.7 & 0.03 & 0.4 \\
\hline
\end{tabular}

**significant difference

Non respiratory-gated images for planning $\mathrm{CT}$ and PET/CT could have hampered the delineation precision and strategy for reducing the PTV margins. When the RTEP5 study was initiated, 4D acquisitions (and IMRT) were not routinely performed in the participating centres. The decision was made to require ungated acquisitions (and 3D conformal radiotherapy) in order to secure our recruitment objectives and the exportability of our results. The majority of our patients had large stage III tumours involving the mediastinum, limiting breathing movements. In addition, our delineation criteria on $18 \mathrm{~F}$-miso PET/CT was validated in free-breathing patients [8]. Precise radiotherapy (4D, IMRT) is indispensable if you want to target tumoral sub-volumes.

Patient selection is another issue. Positive ${ }^{18} \mathrm{~F}$-miso uptake was associated to worse prognosis in our previous RTEP5 study [7]. Ten patients, out of 34 with ${ }^{18} \mathrm{~F}$-miso uptake, were not eligible to the present planning study, mostly because of too large target volumes precluding dose escalation without compromising OAR tolerance. Beyond feasibility studies, randomised trials are warranted to demonstrate the value of radiotherapy assisted by functional imaging.

\section{Conclusion}

Pre-/per-treatment ${ }^{18} \mathrm{FDG}$ and pre-treatment ${ }^{18} \mathrm{~F}$-miso $\mathrm{PET} / \mathrm{CT}$ yield different candidate target volumes for selective increase in radiotherapy dose in patients with NSCLC. Our in-silico study shows that IMRT provides radiotherapy plans matching the pre-defined dose/volume objectives and constraints. Clinical trials are required to select the relevant strategies to improve outcome after concomitant chemo-radiotherapy.

\section{Abbreviations}

BTV: Biologic Target Volume; GTV: Gross Target Volume; IMRT: Intensity modulated Radiation Therapy; NSCLC: Non-small cell lung cancer; OAR: Organs at risk; PTV: Planning Target Volume; RTCT: Radiotherapy - Chemotherapy

\section{Acknowledgements}

This study was supported by a grant from the French National Cancer Institute (PHRC 2011). The authors thank the technologists (E. Auger and S. Vincent) from the Department of Radiotherapy and Medical Physics (Centre Henri Becquerel) for their help in planning.

\section{Funding}

This study was supported by a grant from the French National Cancer Institute (PHRC 2011).

Availability of data and materials

All the data are available in our center at the unit of clinical research.

Authors' contributions

ST, PV, BMD wrote the article. ST, SV, DG and EA collected the data. ST, PG, $\mathrm{SH}$ and NP have been working on data. PB, SH and PG has been working on PET data quality. All authors read and approved the final manuscript.

Ethics approval and consent to participate

All data were extracted from one prospective study (NCT01576796). For all patients, we are a consent.

\section{Consent for publication}

Not applicable

Competing interests

The authors declare that they have no competing interests.

\section{Publisher's Note}

Springer Nature remains neutral with regard to jurisdictional claims in published maps and institutional affiliations.

Received: 14 August 2018 Accepted: 3 October 2018

Published online: 23 October 2018

\section{References}

1. Arriagada R, Le Chevalier T, Quoix E, Ruffie P, de Cremoux H, Douillard JY, et al. ASTRO (American Society for Therapeutic Radiology and Oncology) plenary: effect of chemotherapy on locally advanced non-small cell lung carcinoma: a randomized study of 353 patients. GETCB (Groupe d'Etude et Traitement des cancers Bronchiques), FNCLCC (Féderation Nationale des Centres de Lutte contre le Cancer) and the CEBI trialists. Int J Radiat Oncol Biol Phys. 1991;20(6):1183-90.

2. Wang YC, Tseng $\mathrm{HL}$, Lin $\mathrm{YH}$, Kao CH, Huang $W C$, Huang TC. Improvement of internal tumor volumes of non-small cell lung cancer patients for radiation treatment planning using interpolated average CT in PET/CT. PLoS One. 2013;8(5):e64665.

3. Bradley JD, Paulus R, Komaki R, Masters G, Blumenschein G. Standard-dose versus high-dose conformal radiotherapy with concurrent and consolidation carboplatin plus paclitaxel with or without cetuximab for patients with stage IIIA or IIIB non-small-cell lung cancer (RTOG 0617): a randomised, twoby-two factorial phase 3 study. Lancet Oncol. 2015;16(2):187-99.

4. Garg S, Gielda BT, Kiel K, Turian JV, Fidler MJ, Batus M, et al. Patterns of locoregional failure in stage III non-small cell lung cancer treated with definitive chemoradiation therapy. Pract Radiat Oncol. 2014;4(5):342-8.

5. Machtay M, Paulus R, Moughan J, Komaki R, Bradley JE, Choy H, et al. Defining local-regional control and its importance in locally advanced nonsmall cell lung carcinoma. J Thorac Oncol. 2012;7(4):716-22.

6. Eschmann SM, Paulsen F, Reimold M, Dittmann H, Welz S, Reischl G, Machulla HJ, Bares R. Prognostic impact of hypoxia imaging with 18Fmisonidazole PET in non-small cell lung cancer and head and neck cancer before radiotherapy. J Nucl Med. 2005;46(2):253-60. 
7. Vera P, Thureau S, Chaumet-Riffaud P, Modzelewski R, Bohn P, Vermandel M, et al. Phase II Study of a Radiotherapy Total Dose Increase in Hypoxic Lesions Identified by 18F-Misonidazole PET/CT in Patients with Non-Small Cell Lung Carcinoma (RTEP5 Study). J Nucl Med. 2017;58(7):1045-53.

8. Thureau S, Chaumet-Riffaud P, Modzelewski R, Fernandez P, Tessonnier L, Vervueren $L$, et al. Interobserver agreement of qualitative analysis and tumor delineation of 18F-fluoromisonidazole and 3'-deoxy-3'-18Ffluorothymidine PET images in lung cancer. J Nucl Med. 2013;54(9):1543-50.

9. Giraud P, Antoine M, Larrouy A, Milleron B, Callard P, De Rycke Y, et al. Evaluation of microscopic tumor extension in non-small-cell lung cancer for three-dimensional conformal radiotherapy planning. Int J Radiat Oncol Biol Phys. 2000;48(4):1015-24.

10. Chapet O, Kong FM, Quint LE, Chang AC, Ten Haken RK, Eisbruch A, et al. CT-based definition of thoracic lymph node stations: an atlas from the University of Michigan. Int J Radiat Oncol Biol Phys. 2005;63(1):170-8.

11. Calais J, Thureau S, Dubray B, Modzelewski R, Thiberville L, Gardin I, et al. Areas of high 18F-FDG uptake on preradiotherapy PET/CT identify preferential sites of local relapse after chemoradiotherapy for non-small cell lung cancer. J Nucl Med. 2015;56(2):196-203.

12. Aerts HJ, Bussink J, Oyen WJ, van Elmpt W, Folgering AM, Emans D, et al. Identification of residual metabolic-active areas within NSCLC tumours using a pre-radiotherapy FDG-PET-CT scan: a prospective validation. Lung Cancer. 2012;75(1):73-6.

13. Calais J, Dubray B, Nkhali L, Thureau S, Lemarignier C, Modzelewski R, et al. High FDG uptake areas on pre-radiotherapy PET/CT identify preferential sites of local relapse after chemoradiotherapy for locally advanced oesophageal cancer. Eur J Nucl Med Mol Imaging. 2015;42(6):858-67.

14. Lee NY, Mechalakos JG, Nehmeh S, Lin Z, Squire OD, Cai S, Chan K, Zanzonico PB, Greco C, Ling CC, Humm JL, Schöder H. Fluorine-18-labeled Fluoromisonidazole positron emission and computed tomography-guided intensity-modulated radiotherapy for head and neck Cancer: a feasibility study. Int J Radiat Oncol Biol Phys. 2010. https://doi.org/10.1016/j.jirobp. 2007.06.039 21.

15. Lee N, Nehmeh S, Schoder H, Fury M, Chan K, Ling CC, Humm J. Prospective trial incorporating pre-/mid-treatment [18 F]-misonidazole positron emission tomography for head-and-neck cancer patients undergoing concurrent chemoradiotherapy. Int J Radiat Oncol Biol Phys. 2009;75(1):101-8.

16. Mees G, Dierckx R, Vangestel C, Laukens D, Van Damme N, Van de Wiele C. Pharmacologic activation of tumor hypoxia: a means to increase tumor 2-deoxy-2-[18F]fluoro-D-glucose uptake? Mol Imaging. 2013;12(1):49-58.

17. van Baardwijk A, Dooms C, van Suylen RJ, Verbeken E, Hochstenbag M, Dehing-Oberije C, et al. The maximum uptake of (18)F-deoxyglucose on positron emission tomography scan correlates with survival, hypoxia inducible factor-1alpha and GLUT-1 in non-small cell lung cancer. Eur J Cancer. 2007:43(9):1392-8.

18. Liao ZX, Lee JJ, Komaki R, Gomez DR, O'Reilly M, Allen P, et al. Bayesian randomized trial comparing intensity modulated radiation therapy versus passively scattered proton therapy for locally advanced non-small cell lung cancer. J Clin Oncol. 2016;34(15 suppl):8500

19. J F, Arnold SM, Shelton BJ, Sinha P, Conrad G, Chen L, Rinehart J, McGarry RC. Stereotactic body radiation therapy can be used safely to boost residual disease in locally advanced non-small cell lung cancer: a prospective study. Int J Radiat Oncol Biol Phys. 2013;85(5):1325-31.

\section{Ready to submit your research? Choose BMC and benefit from:}

- fast, convenient online submission

- thorough peer review by experienced researchers in your field

- rapid publication on acceptance

- support for research data, including large and complex data types

- gold Open Access which fosters wider collaboration and increased citations

- maximum visibility for your research: over $100 \mathrm{M}$ website views per year

At BMC, research is always in progress.

Learn more biomedcentral.com/submissions 